\title{
Use of an elemental diet (Vivonex) in the management of bile acid-induced diarrhoea
}

\author{
L. M. NELSON, H. A. CARMICHAEL, R. I. RUSSELL ${ }^{1}$, AND S. T. ATHERTON \\ From the Gastroenterology Unit, Royal Infirmary, Glasgow
}

SUMMARY The effect of a low fat containing elemental diet (Vivonex) on faecal bile acid excretion was studied in six patients with cholerheic diarrhoea, two normal controls, and four patients with non-cholerheic diarrhoea. The total faecal bile acid excretion for the patients with bile acid-induced diarrhoea was significantly reduced from $6.37 \pm 1.64 \mathrm{mmol} / 24 \mathrm{~h}$ (mean $\pm \mathrm{SEM}$ ) to $2.70 \pm 1.12$ $\mathrm{mmol} / 24 \mathrm{~h}$ during Vivonex treatment $(\mathrm{P}<0.05)$. A marked improvement in the diarrhoea of these patients occurred; the number of stools per day decreased and there was less urgency associated with the diarrhoea. No significant reduction in faecal bile acid excretion was observed for the control and non-cholerheic diarrhoea groups. An elemental diet of this type may be of value in the management of patients with bile acid-induced diarrhoea unresponsive to other forms of therapy, and may be of particular value in patients with Crohn's disease.

Cholerheic diarrhoea is an urgent watery diarrhoea caused by excessive amounts of bile acids in the colon as a result of bile acid malabsorption (Hofmann, 1967). Its occurrence after ileal resection of less than $100 \mathrm{~cm}$ and separation from the steatorrhoeic diarrhoea of larger resections has been described (Hofmann, 1972). Severe Crohn's disease of the terminal ileum may also cause cholerheic diarrhoea.

Successful treatment of this type of diarrhoea with the bile acid sequestering agent cholestyramine has been reported (Hofmann and Poley, 1969), but, as bile acids are bound in both the small and large intestines, fat malabsorption occurs with worsening of steatorrhoea and supplementary fat soluble vitamins are needed.

Reports that elemental diets lead to a reduction in faecal bile acid excretion (Crowther et al., 1973; Russell and Gerskowitch, 1974) led to an investigation of the use of one such diet (Vivonex) in the management of patients with cholerheic diarrhoea.

The faecal bile acid excretion before and during Vivonex therapy was measured together with the severity of diarrhoea, and the value of Vivonex assessed clinically in the management of the patients.

${ }^{1}$ Address for correspondence: Dr R. I. Russell, Gastroenterology Unit, Royal Infirmary, Glasgow G4 OSF.

Received for publication 9 February 1977

\section{Methods}

Six patients with cholerheic diarrhoea after ileal resection were studied. Four of the ileal resections had been performed for Crohn's disease, one for carcinoma of the caecum, and one for mesenteric thrombosis. The length of ileum resected ranged from 10 to $100 \mathrm{~cm}$.

Two normal volunteers and four patients with diarrhoea not associated with a markedly raised bile acid excretion ( $<1.5 \mathrm{mmol} / 24 \mathrm{~h}$ ) were also studied. The latter group of patients with non-cholerheic diarrhoea comprised one with chronic pancreatitis, one with a small resection of the terminal ileum, a patient with Crohn's disease, and one with the irritable colon syndrome.

The elemental diet Vivonex that was used in the study contains $0.54 \%$ by weight of fat as highly purified safflower oil $(80 \%$ as triglyceride of linoleic acid), $1.22 \%$ available nitrogen in the form of pure amino acids, and $84.88 \%$ by weight carbohydrate as glucose and oligosaccharides, plus vitamin supplements. An intake of six packets a day thus supplies $2 \cdot 6 \mathrm{~g}$ fat.

Two five-day faecal collections were made. The first during a control period when the patient consumed a normal diet containing $70 \mathrm{~g}$ fat and a second starting three to 10 days after the normal diet had been replaced by Vivonex alone. 
The stools were homogenised using a Silverson mixer-emulsifier and an aliquot dried and analysed for bile acids by a modification of the method of Evrard and Janssen (1968). The methyl esters were chromatographed on a $6^{\prime} \times 3 \mathrm{~mm}$ column of $3 \%$ OV-17 on $100-120$ mesh gas Chrom $Q$ at $275^{\circ} \mathrm{C}$ with $\mathrm{N}_{2}$ as carrier gas. 23-nordeoxycholic acid was used for internal standardisation.

The values for the four major bile acids were summated to give total bile acid excretion. Faecal fat, faecal weight, and stool frequency were also measured in each individual in the control period and again when on Vivonex therapy.

\section{Results}

The Table shows faecal weight, total faecal bile acids, faecal fat and stool frequency before and during Vivonex for each patient together with the intake of Vivonex and length of ileum resected.

For the six patients with cholerheic diarrhoea the mean faecal bile acid output (with SEM) during the control period was $6.37 \pm 1.64 \mathrm{mmol} / 24 \mathrm{~h}$ which was significantly reduced to $2 \cdot 70 \pm 1 \cdot 12$ $\mathrm{mmol} / 24 \mathrm{~h}$ during Vivonex therapy $(\mathrm{P}<0.05$, Wilcoxon's signed ranks test). The mean daily faecal weight for these six patients was $339 \pm 106 \mathrm{~g} /$ $24 \mathrm{~h}$ during the control period: this was significantly reduced to $146 \pm 13 \mathrm{~g} / 24 \mathrm{~h}(\mathrm{P}<0.05)$ during Vivonex therapy. Stool frequency was also reduced in all six patients during Vivonex intake.

The small numbers of patients in the noncholerheic diarrhoea and normal groups preclude statistical analysis and the results are not consistent. Patients 7 and 9 who had faecal fat values indicative of steatorrhoeic diarrhoea showed a large reduction in faecal weight during Vivonex therapy. Although patient 8 had a small ileal resection, he was not included in the cholerheic diarrhoea group because the faecal bile acid output of $1.01 \mathrm{mmol} / 24 \mathrm{~h}$ was not considered sufficient to account for the diarrhoea. However, faecal weight, stool frequency, and bile acid excretion were reduced in this patient during Vivonex therapy.

There was little major problem with the methodology which was used. There was some variation in type of subject, within the control group, although all were normal, and there was some variation in the time in which Vivonex was taken by the control subjects. These two points might be factors in accounting for the range of figures obtained.

Some figures were calculated relating to the accuracy of the methods used. The coefficient of variation obtained within batches tested (one sample analysed 10 times in a batch) was $5.4 \%$. The coefficient of variation between batches (two samples analysed five times each in two batches) was $10.3 \%$. The coefficient of variation of repeated injections of one sample in the GLC was $0.9 \%$. The precision of between-batch variations (using samples with values covering the whole range of faecal bile acids encountered) was $11.4 \%$. These figures were calculated according to the quality control leaflet of the Association of Clinical Biochemists, and suggest that the methodology used in the study gave reasonably reliable results.

Table Details of patients studied, with faecal weight, total faecal bile acids, faecal fat and stool frequency in control period and during Vivonex therapy

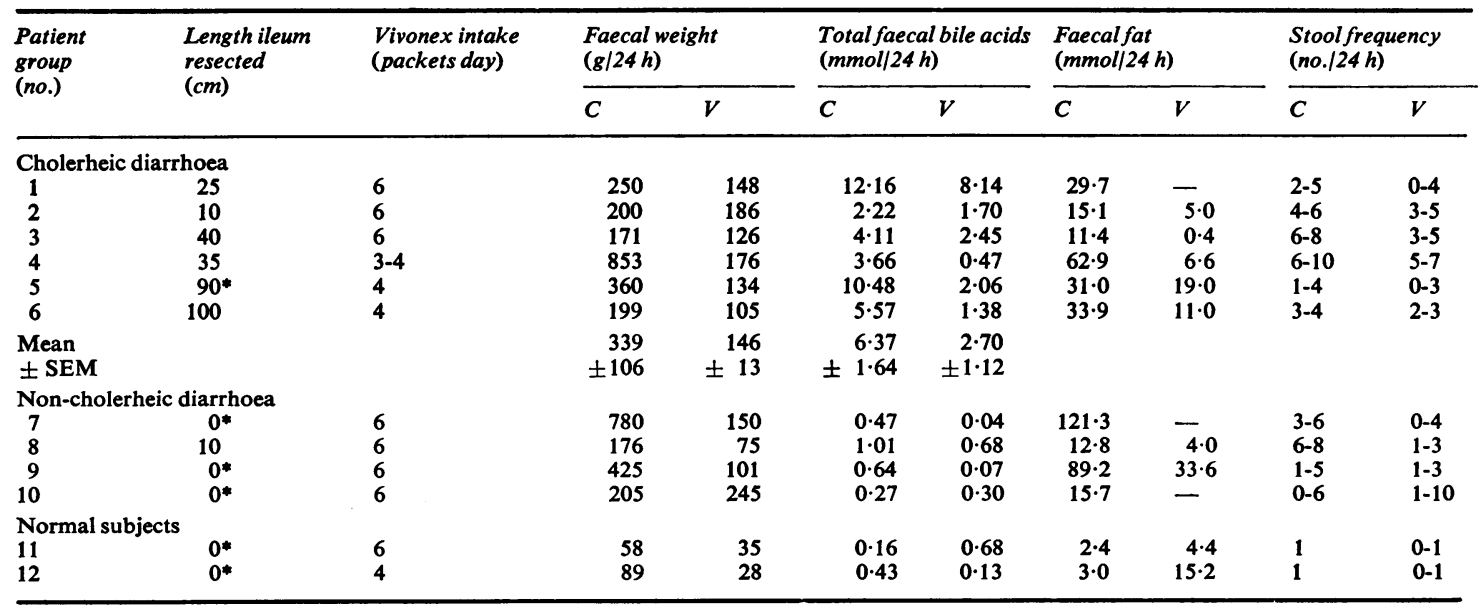




\section{Discussion}

The results of this study show that in the six patients with cholerheic diarrhoea replacement of the normal diet by Vivonex for a period of eight to 15 days resulted in a significant reduction of faecal bile acid output. There was a concomitant improvement in their diarrhoea as measured by faecal weight and stool frequency.

No consistent effect of Vivonex on faecal bile acid output was found in the small numbers of patients with non-cholerheic diarrhoea and normal subjects studied. The marked improvement in the diarrhoea of patients 7 and 9 who had steatorrhoea is probably due to the low fat nature of Vivonex.

Although no evidence is available from this preliminary study regarding the mechanism of the effect of Vivonex in reducing bile acid excretion in patients with cholerheic diarrhoea, the following factors may be considered. Fat and protein restricted diets have been shown to reduce the frequency of enterohepatic cycling of bile acids in man (Hepner, 1975) and in monkeys daily bile salt secretion was reduced by low-fat intake (Campbell et al., 1969). Animal experiments suggest that synthetic diets with a low fibre content and high proportion of 'readily-available' carbohydrate inhibit the conversion of cholesterol to bile acids (Portman et al., 1955; Portman and Murphy, 1958). Increased reabsorption of bile acids might result from a reduction of stool residue, prolonged transit time, and increased stool alkalinity during Vivonex intake (Attebery et al., 1972) or alteration of gut flora (Crowther et al., 1973).

In patients with cholerheic diarrhoea resulting from resection of, or damage to, the terminal ileum, the enterohepatic circulation is broken and most of the bile acid secreted is newly synthesised. In this situation, reduction of bile acid synthesis or secretion may be more important than possible enhancement of reabsorption. A series of experiments to investigate the relative importance of these factors is in progress.

Many patients with Crohn's disease also have bile acid induced diarrhoea resulting from damage to the terminal ileum. In these patients an elemental diet may be of additional advantage as it is readily assimilated and may promote healing of fistulae
(Russell, 1975). The successful use of an elemental diet for long-term nutritional support in Crohn's disease (with and without ileal resection) has also recently been reported (Goode et al., 1976).

Elemental diet therapy or similar dietary control may thus be of value in the management of patients with cholerheic diarrhoea as an alternative to therapy with cholestyramine.

The authors wish to thank Eaton Laboratories for assistance in performing the study, and Miss $\mathrm{H}$. Fleming and Mrs A. Johnstone for technical help. They also wish to thank Professor E. M. McGirr for the provision of laboratory space.

\section{References}

Attebery, H. R., Sutter, V. L., and Finegold, S. M. (1972). Effect of a partially chemically defined diet on normal human fecal flora. American Journal of Clinical Nutrition, 25, 1391-1398.

Campbell, C. B., Spencer, J., and Dowling, R. H. (1969). Bile salt secretion and pool size in Rhesus monkeys with controlled interruption of the enterohepatic circulation. Gut, 10, 1050. (Abstract.)

Crowther, J. S., Drasar, B. S., Goddard, P., Hill, M. J., and Johnson, K. (1973). The effect of chemically defined diet on the faecal flora and faecal steroid concentration. Gut, 14, 790-793.

Evrard, E., and Janssen, G. (1968). Gas-liquid chromatographic determination of human fecal bile acids. Journal of Lipid Research, 9, 226-236.

Goode, A., Hawkins, T., Feggetter, J. G. W., and Johnston, I. D. A. (1976). Use of an elemental diet for long term nutritional support in Crohn's disease. Lancet, 1, 122-124.

Hepner, G. W. (1975). Effect of decreased gallbladder stimulation on enterohepatic cycling and kinetics of bile acids. Gastroenterology, 68, 1574-1581.

Hofmann, A. F. (1967). The syndrome of ileal disease and the broken enterohepatic circulation: cholerheic enteropathy. Gastroenterology, 52, 752-757.

Hofmann, A. F. (1972). Bile acid malabsorption caused by ileal resection. Archives of Internal Medicine, 130, 597-605.

Hofmann, A. F., and Poley, J. R. (1969). Cholestyramine treatment of diarrhoea associated with ileal resection. New England Journal of Medicine, 281, 397-402.

Portman, O. W., Mann, G. V., and Wysocki, A. P. (1955). Bile acid excretion by the rat: nutritional effects. Archives of Biochemistry and Biophysics, 59, 224-232.

Portman, O. W., and Murphy, P. (1958). Excretion of bile acids and B-hydroxysterols by rats. Archives of Biochemistry and Biophysics, 76, 367-376.

Russell, R. I. (1975). Elemental diets. Gut, 16, 68-79.

Russell, R. I., and Gerskowitch, V. P. (1974). Personal communication. 